\title{
Perfusion Culture Biosynthesis
}

National Cancer Institute

\section{Source}

National Cancer Institute. Perfusion Culture Biosynthesis. NCI Thesaurus. Code C112961.

A process that synthesizes a material of interest using a continuously fed cell culture. 